\title{
Calagem e silicatagem superficiais e a disponibilidade de cátions hidrossolúveis em culturas anuais e braquiária ${ }^{1}$
}

\author{
Lyme and silicate surface application and water-soluble cation availability in annual \\ crops and Brachiaria
}

\author{
Gustavo Spadotti Amaral Castro ${ }^{2 *}$, Carlos Alexandre Costa Crusciol² e Marcella Leite de Campos Menegale ${ }^{2}$
}

\begin{abstract}
RESUMO - A eficiência da aplicação superficial de corretivos pode ser melhorada por meio de compostos orgânicos, quantificados através dos cátions hidrossolúveis, liberados por resíduos vegetais. Porém, não se sabe se os teores desses compostos podem ser modificados pela aplicação de calcário e silicato. Objetivou-se com este trabalho avaliar o efeito da aplicação superficial de calcário e silicato no teor de cátions solúveis e condutividade elétrica do extrato da parte aérea das culturas de soja, milheto, aveia branca, braquiária, milho, feijão e guandu. O experimento foi conduzido entre 2006 e 2008 em um Latossolo Vermelho distroférrico em Botucatu-SP, em sistema de semeadura direta consolidado. O delineamento experimental foi em blocos casualizados, com dezesseis repetições. Os tratamentos foram $3,8 \mathrm{tha}^{-1}$ de calcário dolomítico, 4,1 tha ${ }^{-1}$ de silicato de cálcio e magnésio e uma testemunha, sem aplicação de corretivos no solo. Foram determinados os teores de cátions hidrossolúveis e a condutividade elétrica da parte aérea das culturas. Variações nos teores e na somatória de cátions hidrossolúveis não foram detectadas pela condutividade elétrica dos extratos vegetais da parte aérea das culturas. A aplicação dos corretivos elevou os teores de $\mathrm{Ca}^{2+} \mathrm{e} \mathrm{Mg}^{2+}$ solúveis nos extratos dos resíduos de soja, aveia e milheto; para o milho, houve elevação nos teores de $\mathrm{Mg}^{2+}$; além de aumento nos teores de $\mathrm{Mn}^{2+}$ nos resíduos do primeiro ano de braquiária, não havendo, entretanto, influência nos teores nas culturas de feijão, guandu e braquiária no segundo ano.
\end{abstract}

Palavras-chave: Calcário. Silicato de cálcio e magnésio. Resíduos vegetais. Acidez do solo. Sistema de semeadura direta.

\begin{abstract}
The efficiency of the surface application of correctives can be improved by means of organic compounds, quantified by water-soluble cations released by plant residue. However, it is unclear whether the levels of these compounds can be modified by the application of limestone and silicate. The aim of this study was to evaluate the effect of the surface application of limestone and silicate on the levels of soluble cations and the electrical conductivity of the extract from the shoots of soybean, millet, oats, brachiaria, maize, beans and pigeon pea. The experiment was carried out between 2006 and 2008 in dystrophic red latosol in Botucatu SP, under a system of consolidated direct seeding. The experimental design was of randomized blocks, with sixteen replications. The treatments were $3.8 \mathrm{t} \mathrm{ha}^{-1}$ of dolomitic limestone, $4.1 \mathrm{t} \mathrm{ha}^{-1}$ of calcium silicate and magnesium, and a control with no application of correctives to the soil. The levels of water-soluble cations, and the electrical conductivity of the crop shoots were determined. Variations in the levels and sum of water-soluble cations were not detected through the electrical conductivity of the shoot extract. The application of correctives increased the levels of soluble $\mathrm{Ca}^{2+}$ and $\mathrm{Mg}^{2+}$ in extracts from the residue of soybean, oats, and millet; for maize, there was an increase in the concentrations of $\mathrm{Mg}^{2+}$; in addition to increased levels of $\mathrm{Mn}^{2+}$ in the first-year brachiaria residue, with no influence however, on the levels in bean, pigeon pea and brachiaria crops in the second year.
\end{abstract}

Key words: Limestone. Calcium and magnesium silicate. Plant residue. Soil acidity. Direct-seeding system.

\footnotetext{
*Autor para correspondência

${ }^{1}$ Recebido para publicação em 01/08/2011; aprovado em 16/03/2012

Parte da Dissertação de Mestrado do primeiro autor apresentada ao Programa de Pós-Graduação em Agricultura da Universidade Estadual Paulista junto à Faculdade de Ciências Agronômicas, Botucatu-SP; Projeto financiado pela FAPESP

${ }^{2}$ Departamento de Produção Vegetal, Setor Agricultura da Faculdade de Ciências Agronômicas, Universidade Estadual Paulista/UNESP, Campus Botucatu, Caixa Postal 237, Botucatu-SP, Brasil,18.610-307, gsacastro@hotmail.com, crusciol@fca.unesp.br, marcella_lcm@hotmail.com
} 


\section{INTRODUÇÃO}

Resíduos vegetais produzidos por culturas anuais possuem efeito comprovado sobre a mobilidade de cátions no solo, variando de acordo com a espécie (FRANCHINI et al., 2003) e, possivelmente, com o manejo das culturas. A permanência destes resíduos na superfície do solo, aliada à ausência de revolvimento do mesmo, reduzem a taxa de decomposição dos ligantes orgânicos por microrganismos, fazendo com que os compostos orgânicos possam ser solubilizados e lixiviados (MIYAZAWA; PAVAN; FRANCINI, 2000), auxiliando no carreamento dos produtos da dissociação dos corretivos de acidez do solo.

A capacidade dos resíduos vegetais em mobilizar cátions em solos ácidos está intimamente relacionada com o teor de ácidos orgânicos de baixo peso molecular, como os ácidos cítrico e málico. Na planta, tais compostos estão na forma de ânions orgânicos para manutenção da eletroneutralidade química, devido à absorção de cátions básicos (PIERRE; BANWART, 1973); além disso, apesar da existência de ânions inorgânicos $\left(\mathrm{NO}_{3}^{-}, \mathrm{SO}_{4}^{2-}, \mathrm{H}_{2} \mathrm{PO}^{-}\right.$ e $\mathrm{Cl}^{-}$) no tecido vegetal, estes estão presentes em teores pouco significativos. Assim, como a determinação de cátions no tecido vegetal é relativamente mais fácil do que a de ânions orgânicos, a somatória de cátions é um dos melhores indicadores dos efeitos de resíduos na química da solução de solos ácidos (CASSIOLATO et al., 2000; MIYAZAWA; PAVAN; FRANCINI, 2000).

Dessa forma, a determinação da soma de cátions solúveis pode indicar o potencial de mobilização de cátions e as quantidades de $\mathrm{H}^{+}$e $\mathrm{Al}^{3+}$ que podem ser neutralizadas pelos resíduos vegetais, permitindo, assim, carrear Ca trocável para subsuperfície e diminuir o Al trocável do solo (FRANCHINI et al., 1999). A lixiviação de $\mathrm{Ca}^{2+}$ e $\mathrm{Mg}^{2+}$ é facilitada pela ligação desses cátions a compostos orgânicos, tornando-os quimicamente neutros, evitando sua adsorção aos coloides do solo. $\mathrm{Na}$ presença de $\mathrm{H}^{+}$ou $\mathrm{Al}^{3+}$, estes cátions ligados aos compostos orgânicos tendem a ser substituídos por $\mathrm{H}^{+}$ou $\mathrm{Al}^{3+}$, formando assim, compostos estáveis protonados ou complexo Al-orgânico (MIYAZAWA; PAVAN; FRANCHINI, 2000),

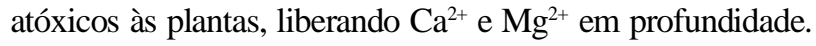
Nestesentido,Diehl,Miyazawae Takahashi(2008) verificaram que os compostos orgânicos dos extratos vegetais apresentam correlação significativa com as alterações de pH, Al trocável, $\mathrm{H}+\mathrm{Al}$ e a saturação por bases nas colunas de solo.

O material mais utilizado no Brasil como corretivo de acidez do solo é o calcário, porém os silicatos provenientes das escórias de aciaria são materiais que se comportam de forma semelhante aos calcários. De acordo com Korndörfer, Pereira e Camargo (2002), os silicatos de $\mathrm{Ca}$ e $\mathrm{Mg}$, por apresentarem composição semelhante a dos carbonatos, podem substituir os calcários com vantagens, podendo assim sua recomendação de aplicação ser baseada em qualquer um dos métodos utilizados para recomendação de calagem. Além disso, a presença do Si no material, elemento benéfico, leva à formação de dupla camada de sílica-cutícula e sílica-celulose quando depositado na parede celular da epiderme das folhas, podendo alterar a composição bioquímica das culturas e também a taxa de decomposição dos seus restos vegetais (MA; YAMAJI, 2006).

Desta forma, objetivou-se comparar os efeitos da aplicação superficial de calcário e de silicato nos teores de cátions solúveise nacondutividadeelétrica dos extratos vegetais da parte aérea das culturas da soja, milheto, aveia, braquiária, milho, feijão e guandu, na época do florescimento.

\section{MATERIAL E MÉTODOS}

\section{Localização e Caracterização da Área Experimental}

O experimento foi conduzido durante duas safras agrícolas, entre outubro de 2006 e julho de 2008, na Fazenda Experimental Lageado, pertencente à Faculdade de Ciências Agronômicas - UNESP, localizada no município de Botucatu (SP), nas coordenadas geográficas de $22^{\circ} 51^{\prime} \mathrm{S}$ e $48^{\circ} 23^{\prime} \mathrm{W}$, com altitude de $765 \mathrm{~m}$. O solo do local é do tipo Latossolo Vermelho distroférrico típico argiloso, profundo, ácido (EMPRESA BRASILEIRA DE PESQUISA AGROPECUÁRIA, 2006). De acordo com a classificação de Köeppen, o clima predominante na região é do tipo Cwa, caracterizado por clima tropical de altitude, com inverno seco e verão quente e chuvoso.

Para a determinação das características químicas do solo, amostrou-se a camada 0-20 m, seguindo a metodologia descrita por Raij et al. (2001). Os resultados foram: matéria orgânica de 18,25 $\mathrm{g} \mathrm{dm}^{-3}, \mathrm{pH}\left(\mathrm{CaCl}_{2}\right)$ de 4,2, $\mathrm{P}$ (resina) de 3,62 $\mathrm{mg} \mathrm{dm}^{-3}, \mathrm{~K}, \mathrm{Ca}, \mathrm{Mg}$ e CTC de 0,76, 11,62, 5,75 e $74,98 \mathrm{mmol}_{\mathrm{c}} \mathrm{dm}^{-3}$, respectivamente, e V\% de $24,2 \%$.

\section{Delineamento Experimental e Tratamentos Empregados}

O delineamento experimental utilizado foi em blocos casualizados com dezesseis repetições para cada cultura estudada. Para comparação entre as culturas, foi realizada a comparação de médias pela análise conjunta dos dados. As parcelas $(5,4 \times 10 \mathrm{~m})$ foram constituídas por uma testemunha e dois corretivos, aplicadas superficialmente, em 14/10/2006, nas quantidades $3,8 \mathrm{t} \mathrm{ha}^{-1}$ do calcário e $4,1 \mathrm{t} \mathrm{ha}^{-1}$ do silicato.

Os materiais corretivos utilizados foram o calcário dolomítico $(\mathrm{PRNT}=90 \%, \mathrm{CaO}=36 \%$ e $\mathrm{MgO}=12 \%)$ e o Agrosilício $^{\circledR}$ (silicato de cálcio e magnésio/ PRNT $=80 \%$, $\mathrm{CaO}=34 \%, \mathrm{MgO}=10 \%$ e $\mathrm{SiO}_{2}=22 \%$ ). As doses dos corretivos foram calculadas objetivando elevar a saturação por bases (V\%) a $70 \%$. 


\section{Instalação e Condução do Experimento}

A cultura da soja, cultivar Embrapa 48, foi semeda no dia 29 de novembro de 2006, sobre 4,0 t ha de $^{-1}$ biomassa aérea de milheto previamente dessecado com $1.800 \mathrm{~g}$ de i.a. de glyphosate por hectare, obedecendo um espaçamento de $0,45 \mathrm{~m}$ nas entrelinhas e 22 plantas por metro. Para a adubação de base nos sulcos foram utilizados $250 \mathrm{~kg} \mathrm{ha}^{-1}$ da formulação 04-20-20, levando-se em conta as características químicas do solo e as recomendações para a cultura da soja (RAIJ et al., 1997). Decorridos cinquenta dias da semeadura, ocorreu o florescimento da cultura.

$\mathrm{Na}$ entressafra, a área experimental foi seccionada em quatro faixas, sendo três delas ocupadas por culturas e uma mantida em pousio. As culturas de entressafra (milheto, aveia branca e braquiária) foram semeadas no dia 10 de abril de 2007, obedecendo também o espaçamento de $0,45 \mathrm{~m}$. Para a semeadura do milheto (cultivar BRS 1501) utilizou-se $25 \mathrm{~kg}$ de sementes por hectare, objetivando população de 300 mil plantas por hectare. Aos cinqüenta dias após a semeadura ocorreu o florescimento pleno da cultura. Para a aveia branca, utilizou-se a cultivar IAC 7, sendo semeadas 133 sementes viáveis por metro quadrado. A cultura também floresceu cinqüenta dias após a semeadura. Por fim, como forrageira, utilizou-se a Brachiaria ruziziensis, na densidade de semeadura de $10 \mathrm{~kg} \mathrm{ha}^{-1}$ para o valor cultural de $25 \%$, com o objetivo de semear $2,5 \mathrm{~kg}$ de sementes puras viáveis por hectare. A braquiária permaneceu vegetando até dezembro de 2007, antes da instalação da cultura de verão. As culturas de entressafra não receberam qualquer tipo de adubação.

No segundo ano agrícola, na área em pousio, posteriormente ao cultivo da soja, semeou-se (2/12/2007) o híbrido de milho 2B570, de ciclo médio e exigente em fertilidade do solo, no espaçamento de $0,45 \mathrm{~m}$ entrelinhas e sementes necessárias para se obter 3 plantas por metro. A adubação de semeadura foi $300 \mathrm{~kg} \mathrm{ha}^{-1}$ da formulação 08-28-16, levando-se em conta as características químicas do solo e as recomendações para a cultura do milho (RAIJ et al., 1997). Posteriormente, em 10 de janeiro de 2008, realizou-se adubação de cobertura com $200 \mathrm{~kg} \mathrm{ha}^{-1} \mathrm{de}$ uréia na entrelinha das parcelas. O florescimento pleno do milho ocorreu 64 dias após sua emergência e a colheita foi realizada no dia 1 de abril de 2007.

Nesta entressafra, assim como na anterior, a área experimental foi seccionada em quatro faixas, sendo uma mantida em pousio e três delas ocupadas pelas culturas feijão, guandu e braquiária. As culturas de entressafra foram semeadas no dia 5 de abril de 2008, seguindo o espaçamento de $0,45 \mathrm{~m}$. Na cultura do feijão a cultivar Pérola foi semeada utilizando-se 18 sementes por metro, e seu florescimento pleno ocorreu 47 dias após a semeadura. Para a cultura do guandu semeou-se 20 sementes por metro da cultivar IAPAR 43. O florescimento pleno ocorreu 87 dias após a semeadura (1/07/2008). A cultura da braquiária foi implantada na mesma densidade e espaçamento utilizados no primeiro ano, permanecendo em livre crescimento até outubro de 2008.

\section{Amostragens e Avaliações Realizadas}

Para a determinação dos teores de cátions hidrossolúveis das culturas anuais, foram coletadas amostras de folhas no momento do florescimento, exceto para a braquiária que foi amostrada antes da dessecação para semeadura da cultura de verão. As folhas foram colocadas para secagem em estufa com circulação forçada de ar a $60-70{ }^{\circ} \mathrm{C}$, por 72 horas, sendo em seguida moídas em moinho tipo Willey. Para extração dos compostos hidrossolúveis (ácidos orgânicos de baixo peso molecular), $1 \mathrm{~g}$ dos resíduos foi transferido para frascos de $100 \mathrm{~mL}$, em seguida, adicionados $50 \mathrm{~mL}$ de água destilada, agitando-se por 4 horas a uma velocidade de $200 \mathrm{rpm}$, com posterior filtragem em papel-filtro qualitativo de filtragem rápida.

De posse dos extratos vegetais, foi realizada a leitura dos teores de $\mathrm{Ca}^{2+}, \mathrm{Mg}^{2+}, \mathrm{Mn}^{2+}, \mathrm{Cu}^{2+}, \mathrm{Fe}^{3+}$ e $\mathrm{Zn}^{2+}$ por espectrometria de absorção atômica; já a leitura dos teores de $\mathrm{K}^{+}$foi realizada por fotometria de chama. Os resultados foram expressos em mmol $\mathrm{kg}^{-1}$, de forma individual para cada elemento e na forma de soma de cátions $\left(\sum \mathrm{Ca}^{2+}, \mathrm{Mg}^{2+}\right.$, $\mathrm{K}^{+}, \mathrm{Mn}^{2+}, \mathrm{Cu}^{2+}, \mathrm{Fe}^{3+}$ e $\left.\mathrm{Zn}^{2+}\right)$. A partir do extrato vegetal, determinou-se, também, a condutividade elétrica da solução (CE) por condutivimetria, em $\mu \mathrm{S} \mathrm{cm}^{-1}$, segundo metodologia descrita por Miyazawa, Pavan e Franchini (2000).

\section{Análise Estatística}

Os resultados foram submetidos à análise de variância, sendo as médias referentes à aplicação dos corretivos comparadas pelo teste t (DMS) a $5 \%$. Posteriormente, para a comparação entre as espécies realizou-se a análise conjunta dos dados, uma vez que a razão entre o maior e o menor quadrado médio residual não foi superior a sete (BANZATTO; KRONKA, 1995).

\section{RESULTADOS E DISCUSSÃO}

Para a cultura da soja (Tabela 1) observou-se elevação dos teores de $\mathrm{Ca}^{2+}$ e $\mathrm{Mg}^{2+}$ solúveis quando submetidos à aplicação de corretivos. Este resultado pode ser explicado pelo fato de ambos os materiais empregados serem fontes desses nutrientes, ocasionando, portanto, maior acúmulo dos mesmos. Os teores de $\mathrm{K}^{+}, \mathrm{Mn}^{2+}$, $\mathrm{Cu}^{2+}, \mathrm{Fe}^{3+}$ e $\mathrm{Zn}^{2+}$ não foram alterados pela aplicação dos corretivos. No entanto, os baixos valores de $\mathrm{K}$ podem ser explicados pela ocorrência de chuvas ao longo do período que antecedeu a coleta das folhas, favorecendo, assim, a 
Tabela 1 - Teores de cátions solúveis, somatória dos cátions ${ }^{(1)}$ e condutividade elétrica ${ }^{(2)}$ do extrato vegetal de soja após a aplicação superficial de corretivos em Sistema de Semeadura Direta

\begin{tabular}{|c|c|c|c|c|c|c|c|c|c|}
\hline \multirow{3}{*}{ Tratamentos } & \multicolumn{8}{|c|}{ Cátions solúveis no extrato vegetal de soja } & \multirow{2}{*}{$\mathrm{CE}^{(2)}$} \\
\hline & $\mathrm{K}^{+}$ & $\mathrm{Ca}^{2+}$ & $\mathrm{Mg}^{2+}$ & $\mathrm{Mn}^{2+}$ & $\mathrm{Cu}^{2+}$ & $\mathrm{Fe}^{3+}$ & $\mathrm{Zn}^{2+}$ & $\Sigma^{(1)}$ & \\
\hline & \multicolumn{8}{|c|}{$\left(\mathrm{mmol}_{\mathrm{c}} \mathrm{kg}^{-1}\right)$} & $\mu \mathrm{S} \mathrm{cm}^{-1}$ \\
\hline Testemunha & 66,9 & $142 \mathrm{~b}$ & $238 \mathrm{~b}$ & 2,67 & 0,69 & 0,88 & 1,10 & $453 b$ & 1.611 \\
\hline Calcário & 65,3 & $170 \mathrm{a}$ & $267 \mathrm{a}$ & 2,77 & 0,71 & 1,06 & 1,13 & $532 \mathrm{a}$ & 1.761 \\
\hline Silicato & 69,6 & $194 a$ & $263 a$ & 2,45 & 0,67 & 1,01 & 1,12 & $508 \mathrm{a}$ & 1.773 \\
\hline $\mathrm{F}_{\text {calc. }}$ & $1,34^{\mathrm{ns}}$ & $8,74 * *$ & $4,26^{*}$ & $0,62^{\text {ns }}$ & $0,55^{\text {ns }}$ & $0,93^{\mathrm{ns}}$ & $0,53^{\text {ns }}$ & $7,76^{* *}$ & $1,06^{\mathrm{ns}}$ \\
\hline $\mathrm{CV}(\%)$ & 11,18 & 20,67 & 11,65 & 31,30 & 16,38 & 38,48 & 20,18 & 11,65 & 20,38 \\
\hline DMS & 5,43 & 25,2 & 21,5 & 0,52 & 0,12 & 0,29 & 0,31 & 50,0 & 252,4 \\
\hline
\end{tabular}

**, * e ns, significativo a $1 \%, 5 \%$ e não significativo, respectivamente, pelo Teste F. Médias seguidas de letras distintas na coluna diferem estatisticamente pelo teste $\mathrm{t}(\mathrm{p}<0,05)$

lavagem do nutriente do material vegetal (ROSOLEM et al., 2007), já que este é um nutriente altamente móvel no floema que forma ligações com complexos orgânicos de fácil reversibilidade (MALAVOLTA, 1997).

A aplicação de corretivos proporcionou aumento na soma de cátions solúveis nos extratos do resíduo da soja, principalmente por aumentar o teor de $\mathrm{Ca}^{2+} \mathrm{e} \mathrm{Mg}^{2+}$ solúveis no resíduo. Como a soma de cátions solúveis indica a quantidade de $\mathrm{H}^{+} \mathrm{eAl}^{3+}$ que pode ser neutralizada pelos resíduos vegetais (MIYAZAWA, PAVAN; FRANCINI, 2000), a calagem e a silicatagem em superfície podem também melhorar a capacidade dos resíduos das plantas cultivadas na área em mobilizar cátions e imobilizar o $\mathrm{Al}^{3+}$ da solução do solo, além de agirem diretamente na correção da acidez do solo e na

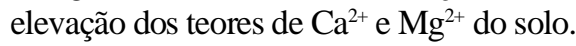

Por outro lado, não se observou correspondente aumento da condutividade elétrica do extrato. Possivelmente a quantidade de sais não foi suficiente para alterar significativamente o valor desta variável, o que pode indicar a necessidade da quantificação de outros cátions solúveis. Tais resultados concordam com os obtidos por Soratto e Crusciol (2007), que trabalharam com doses de calcário em um solo de mesma classificação, e constataram ausência de resposta na soma de cátions e da condutividade elétrica do extrato vegetal de feijão, mesmo com a redução dos teores de $\mathrm{Mg}^{2+}$ solúveis 18 meses após a aplicação superficial do corretivo. Neste estudo, os referidos autores quantificaram apenas os valores de $\mathrm{K}^{+}, \mathrm{Ca}^{2+}, \mathrm{Mg}^{2+} \mathrm{e} \mathrm{Mn}^{2+}$ solúveis. Porém, mesmo com a quantificação dos cátions $\mathrm{Cu}^{2+}, \mathrm{Fe}^{3+} \mathrm{e} \mathrm{Zn}^{2+}$ no presente trabalho, ainda não foram observadas alterações que causassem efeito no somatório de cátions, sugerindo que a quantificação de outros cátions, como o $\mathrm{Na}^{+}$e o $\mathrm{NH}_{4}^{+}$, possam ser necessárias para detectar alterações nesta variável.

$\mathrm{Na}$ cultura da braquiária, em seu primeiro ano de cultivo, somente o $\mathrm{Mn}^{2+}$ foi influenciado pela aplicação dos corretivos (Tabela 2), levando a uma diminuição nos seus teores. Silva e Lemos (2008) observaram a mesma situação quando analisaram extratos de resíduos de feijão cv. Pérola mediante aplicação superficial de calcário, onde o teor de $\mathrm{Mn}^{2+}$ dos resíduos foi menor quando comparado à testemunha, sem aplicação do corretivo. A redução dos teores desse elemento pode ser explicada pela diminuição da disponibilidade desse nutriente à medida que o $\mathrm{pH}$ do soloé elevado pela aplicação dos corretivos, principalmente na camada superficial (HARMSEN; VLEK, 1985).

Os valores de somatório de cátions e de condutividade elétrica dos extratos não foram alterados pela aplicação dos tratamentos. Isso ocorreu devido ao efeito do teor de $\mathrm{Mn}^{2+}$, que corresponde a menos de 5\% do valor do somatório de cátions, pouco influenciando o resultado final do mesmo.

Na cultura da aveia branca, constatou-se aumento significativo nos teores de $\mathrm{Ca}^{2+} \mathrm{e} \mathrm{Mg}^{2+}$ (Tabela 3), como observado na soja. Soratto e Crusciol (2007) observaram aumento no teor de $\mathrm{Ca}^{2+}$ e diminuição no teor de $\mathrm{Mg}^{2+}$ em plantas de aveia preta mediante aplicação de calcário e concluíram que, o excesso de $\mathrm{Ca}^{2+}$ pode ter prejudicado a absorção de $\mathrm{Mg}^{2+}$ pela cultura. Diehl, Miyazawa e Takahashi (2008) verificaram que os resíduos de aveia foram eficientes na neutralização da acidez e mobilização de cátions polivalentes devido ao seu alto teor de $\mathrm{K}^{+}$ iônico. Por outro lado, Marques (2011) observou aumento nos teores de $\mathrm{Mg}^{2+}$, e diminuição nos teores de $\mathrm{Fe}^{3+} \mathrm{em}$ plantas de aveia branca mediante aplicação de calcário. $\mathrm{O}$ autor justificou o resultado pela elevação do $\mathrm{pH}$ do solo decorrente da aplicação do calcário, que forneceu $\mathrm{Mg}^{2+}$, porém reduziu os valores de $\mathrm{Fe}^{3+}$ disponíveis à planta. Da mesma forma que para a cultura da soja, o aumento nos teores de $\mathrm{Ca}^{2+}$ e $\mathrm{Mg}^{2+}$ no extrato vegetal da aveia branca refletiu em aumento da somatória de cátions, não alterando, porém, os valores de condutividade elétrica. 
Tabela 2 - Teores de cátions solúveis, somatória dos cátions ${ }^{(1)}$ e condutividade elétrica ${ }^{(2)}$ do extrato vegetal de braquiária (cultivada após soja) após a aplicação superficial de corretivos em Sistema de Semeadura Direta

\begin{tabular}{|c|c|c|c|c|c|c|c|c|c|}
\hline \multirow{3}{*}{ Tratamento } & \multicolumn{8}{|c|}{ Cátions solúveis no extrato vegetal de braquiária } & \multirow{2}{*}{$\mathrm{CE}^{(2)}$} \\
\hline & $\mathrm{K}^{+}$ & $\mathrm{Ca}^{2+}$ & $\mathrm{Mg}^{2+}$ & $\mathrm{Mn}^{2+}$ & $\mathrm{Cu}^{2+}$ & $\mathrm{Fe}^{3+}$ & $\mathrm{Zn}^{2+}$ & $\Sigma^{(1)}$ & \\
\hline & \multicolumn{8}{|c|}{$\left(\mathrm{mmol}_{\mathrm{c}} \mathrm{kg}^{-1}\right)$} & $\mu \mathrm{Scm}^{-1}$ \\
\hline Testemunha & 280 & 31,8 & 29,2 & $13,6 \mathrm{a}$ & 0,53 & 0,96 & 0,97 & 355 & 2.253 \\
\hline Calcário & 269 & 34,3 & 29,9 & $12,3 b$ & 0,55 & 0,96 & 0,93 & 349 & 2.276 \\
\hline Silicato & 276 & 35,1 & 32,3 & $11,5 b$ & 0,52 & 1,04 & 0,92 & 358 & 2.338 \\
\hline $\mathrm{F}_{\text {calc. }}$ & $0,45^{\mathrm{ns}}$ & $1,69^{\text {ns }}$ & $1,71^{\mathrm{ns}}$ & $11,85^{*}$ & $0,37^{\mathrm{ns}}$ & $0,29^{\mathrm{ns}}$ & $0,67^{\mathrm{ns}}$ & $0,27^{\mathrm{ns}}$ & $0,16^{\mathrm{ns}}$ \\
\hline $\mathrm{CV}(\%)$ & 8,66 & 11,02 & 11,59 & 6,89 & 13,21 & 15,71 & 8,11 & 7,19 & 13,64 \\
\hline DMS & 25,5 & 3,9 & 3,7 & 0,9 & 0,08 & 0,27 & 0,07 & 27,3 & 335,8 \\
\hline
\end{tabular}

**, * e ns, significativo a $1 \%, 5 \%$ e não significativo, respectivamente, pelo Teste F. Médias seguidas de letras distintas na coluna diferem estatisticamente pelo teste $\mathrm{t}(\mathrm{p}<0,05)$

Tabela 3 - Teores de cátions solúveis, somatória dos cátions ${ }^{(1)}$ e condutividade elétrica ${ }^{(2)}$ do extrato vegetal de aveia branca após a aplicação superficial de corretivos em Sistema de Semeadura Direta

\begin{tabular}{|c|c|c|c|c|c|c|c|c|c|}
\hline \multirow{3}{*}{ Tratamento } & \multicolumn{8}{|c|}{ Cátions solúveis no extrato vegetal de aveia branca } & \multirow{2}{*}{$\mathrm{CE}^{(2)}$} \\
\hline & $\mathrm{K}^{+}$ & $\mathrm{Ca}^{2+}$ & $\mathrm{Mg}^{2+}$ & $\mathrm{Mn}^{2+}$ & $\mathrm{Cu}^{2+}$ & $\mathrm{Fe}^{3+}$ & $\mathrm{Zn}^{2+}$ & $\Sigma^{(1)}$ & \\
\hline & \multicolumn{8}{|c|}{$\left(\mathrm{mmol}_{\mathrm{c}} \mathrm{kg}^{-1}\right)$} & $\mu \mathrm{S} \mathrm{cm}^{-1}$ \\
\hline Testemunha & 200 & $81,5 b$ & $20,0 b$ & 11,9 & 0,3 & 0,66 & 0,14 & $315 b$ & 1.697 \\
\hline Calcário & 202 & $90,5 \mathrm{a}$ & $25,1 \mathrm{a}$ & 11,7 & 0,31 & 0,66 & 0,15 & $330 \mathrm{a}$ & 1.794 \\
\hline Silicato & 199 & $92,6 \mathrm{a}$ & $24,7 \mathrm{a}$ & 11,0 & 0,32 & 0,65 & 0,15 & $329 \mathrm{a}$ & 1.748 \\
\hline $\mathrm{F}_{\text {calc. }}$ & $0,24^{\mathrm{ns}}$ & $2,91 *$ & $7,03 *$ & $0,53^{\mathrm{ns}}$ & $0,64^{\mathrm{ns}}$ & $0,11^{\mathrm{ns}}$ & $1,91^{\mathrm{ns}}$ & $2,76^{*}$ & $1,02^{\mathrm{ns}}$ \\
\hline CV (\%) & 10,9 & 11,06 & 13,07 & 15,43 & 7,54 & 21,75 & 12,84 & 8,62 & 8,3 \\
\hline DMS & 6,3 & 7,2 & 3,6 & 1,9 & 0,18 & 0,12 & 0,07 & 10,3 & 160,3 \\
\hline
\end{tabular}

**, * e ns, significativo a $1 \%, 5 \%$ e não significativo, respectivamente, pelo Teste F. Médias seguidas de letras distintas na coluna diferem estatisticamente pelo teste $\mathrm{t}(\mathrm{p}<0,05)$

Analisando-se os resultados de milheto (Tabela 4), o único cátion que sofreu influência dos tratamentos foi o $\mathrm{Ca}^{2+}$, onde as plantas que receberam aplicação dos corretivos continham valores superiores ao da testemunha. Entretanto, tal aumento não foi suficiente para alterar a somatória de cátions, nem a condutividade elétrica. Silva e Lemos (2008), avaliando os extratos de plantas de milheto mediante aplicação de doses de calcário em Latossolo Vermelho distrófico, observaram que não houve diferença no teor de $\mathrm{Ca}^{2+}$ solúvel do extrato vegetal. Tal fato comprova que, em certos experimentos, mesmo com modificações químicas no solo provocadas pela aplicação de corretivos, os teores de cátions na parte aérea das culturas podem ser inalterados (CAIRES; BLUM; BARTH, 2003).

Na cultura do milho (Tabela 5), somente os teores de $\mathrm{Mg}^{2+}$ foram alterados pela aplicação de corretivos. A elevação dos teores de $\mathrm{Mg}^{2+}$ foi decorrente da presença desse elemento nos corretivos, pois ambos possuem quantidades significativas de $\mathrm{MgO}$. No entanto, os teores de Ca não foram alterados, possivelmente pelo suprimento adequado da área que não recebeu os corretivos, pois o teor original de $\mathrm{Ca}^{2+}$ do solo foi considerado alto (RAIJ et al. 1997). Como a concentração de $\mathrm{Mg}^{2+}$ solúvel na folha foi muito inferior a dos outros dois principais cátions $\left(\mathrm{K}^{+}\right.$e $\left.\mathrm{Ca}^{2+}\right)$, a alteração proporcionada pelos corretivos não refletiu na elevação da soma de cátions nem na condutividade elétrica dos extratos.

No segundo ano de cultivo da Brachiaria ruziziensis a aplicação dos corretivos também não alteraram os teores de cátions solúveis (Tabela 6), assim como ocorreu no primeiro ano (Tabela 2), com exceção para o $\mathrm{Mn}^{2+}$. Ressalta-se que a forrageira utilizada é caracterizada como planta rústica, sendo considerada moderadamente tolerante à acidez do solo e com boa capacidade de se desenvolver em solos pobres (RAIJ et al., 1997), justificando assim a ausência de efeito sobre os cátions solúveis em função da aplicação dos corretivos. 
Tabela 4 - Teores de cátions solúveis, somatória dos cátions ${ }^{(1)}$ e condutividade elétrica ${ }^{(2)}$ do extrato vegetal de milheto após a aplicação superficial de corretivos em Sistema de Semeadura Direta

\begin{tabular}{|c|c|c|c|c|c|c|c|c|c|}
\hline \multirow{3}{*}{ Tratamento } & \multicolumn{8}{|c|}{ Cátions solúveis no extrato vegetal de milheto } & \multirow{2}{*}{$\mathrm{CE}^{(2)}$} \\
\hline & $\mathrm{K}^{+}$ & $\mathrm{Ca}^{2+}$ & $\mathrm{Mg}^{2+}$ & $\mathrm{Mn}^{2+}$ & $\mathrm{Cu}^{2+}$ & $\mathrm{Fe}^{3+}$ & $\mathrm{Zn}^{2+}$ & $\Sigma^{(1)}$ & \\
\hline & \multicolumn{8}{|c|}{$\left(\mathrm{mmol}_{\mathrm{c}} \mathrm{kg}^{-1}\right)$} & $\mu \mathrm{S} \mathrm{cm}^{-1}$ \\
\hline Testemunha & 152 & $13,2 b$ & 73,3 & 13,2 & 0,48 & 0,28 & 1,39 & 253 & 1.867 \\
\hline Calcário & 155 & $18,3 \mathrm{a}$ & 78,5 & 12,9 & 0,47 & 0,27 & 1,35 & 267 & 1.988 \\
\hline Silicato & 154 & $17,5 \mathrm{a}$ & 81,5 & 11,5 & 0,49 & 0,29 & 1,39 & 267 & 1.979 \\
\hline $\mathrm{F}_{\text {calc. }}$ & $0,5^{\mathrm{ns}}$ & $4,04 *$ & $1,57^{\mathrm{ns}}$ & $0,71^{\mathrm{ns}}$ & $0,26^{\mathrm{ns}}$ & $0,16^{\mathrm{ns}}$ & $0,17^{\mathrm{ns}}$ & $1,63^{\mathrm{ns}}$ & $0,49^{\text {ns }}$ \\
\hline CV (\%) & 14,08 & 23,35 & 20,08 & 20,16 & 13,55 & 21,97 & 11,73 & 10,39 & 14,05 \\
\hline DMS & 24,4 & 4,0 & 16,1 & 3,1 & 0,07 & 0,11 & 0,22 & 25,4 & 294,3 \\
\hline
\end{tabular}

**, * e ns, significativo a $1 \%, 5 \%$ e não significativo, respectivamente, pelo Teste F. Médias seguidas de letras distintas na coluna diferem estatisticamente pelo teste $\mathrm{t}(\mathrm{p}<0,05)$

Tabela 5 - Teores de cátions solúveis, somatória dos cátions ${ }^{(1)}$ e condutividade elétrica ${ }^{(2)}$ do extrato vegetal de milho após a aplicação superficial de corretivos em Sistema de Semeadura Direta

\begin{tabular}{lccccccccc}
\hline & \multicolumn{7}{c}{ Cátions solúveis no extrato vegetal de milho } & \multirow{2}{*}{$\mathrm{CE}^{(2)}$} \\
\cline { 2 - 7 } Tratamento & $\mathrm{K}^{+}$ & $\mathrm{Ca}^{2+}$ & $\mathrm{Mg}^{2+}$ & $\mathrm{Mn}^{2+}$ & $\mathrm{Cu}^{2+}$ & $\mathrm{Fe}^{3+}$ & $\mathrm{Zn}^{2+}$ & $\Sigma^{(1)}$ & \\
\cline { 2 - 7 } & 159 & 43,2 & $17,4 \mathrm{~b}$ & 8,2 & 0,31 & 0,61 & 0,37 & 230 & 1.323 \\
\hline Testemunha & $\left.15 \mathrm{~kg}^{-1}\right)$ & & & & \\
Calcário & 161 & 47,6 & $19,7 \mathrm{a}$ & 7,9 & 0,33 & 0,61 & 0,38 & 238 & 1.363 \\
Silicato & 164 & 46,0 & $19,0 \mathrm{a}$ & 8,0 & 0,32 & 0,62 & 0,39 & 238 & 1.374 \\
$\mathrm{~F}_{\text {calc. }}$ & $0,30^{\text {ns }}$ & $1,04^{\text {ns }}$ & $4,59^{*}$ & $0,69^{\text {ns }}$ & $0,29^{\text {ns }}$ & $0,19^{\text {ns }}$ & $0,23^{\text {ns }}$ & $1,21^{\text {ns }}$ & $0,47^{\text {ns }}$ \\
CV $(\%)$ & 8,53 & 12,27 & 11,28 & 16,85 & 20,09 & 9,5 & 11,45 & 4,56 & 4,93 \\
DMS & 10,5 & 4,5 & 1,4 & 1,1 & 0,05 & 0,05 & 0,03 & 10,3 & 41,3 \\
\hline
\end{tabular}

$* \mathrm{e}^{\text {ns }}$, significativo a $1 \%, 5 \%$ e não significativo, respectivamente, pelo Teste F. Médias seguidas de letras distintas na coluna diferem estatisticamente pelo teste $\mathrm{t}(\mathrm{p}<0,05)$

Tabela 6 - Teores de cátions solúveis, somatória dos cátions ${ }^{(1)}$ e condutividade elétrica ${ }^{(2)}$ do extrato vegetal de braquiária (cultivada após milho) após a aplicação superficial de corretivos em Sistema de Semeadura Direta

\begin{tabular}{|c|c|c|c|c|c|c|c|c|c|}
\hline \multirow{3}{*}{ Tratamentos } & \multicolumn{8}{|c|}{ Cátions solúveis no extrato vegetal de braquiária } & \multirow{2}{*}{$\mathrm{CE}^{(2)}$} \\
\hline & $\mathrm{K}^{+}$ & $\mathrm{Ca}^{2+}$ & $\mathrm{Mg}^{2+}$ & $\mathrm{Mn}^{2+}$ & $\mathrm{Cu}^{2+}$ & $\mathrm{Fe}^{3+}$ & $\mathrm{Zn}^{2+}$ & $\Sigma^{(1)}$ & \\
\hline & \multicolumn{8}{|c|}{$\left(\mathrm{mmol}_{\mathrm{c}} \mathrm{kg}^{-1}\right)$} & $\mu \mathrm{S} \mathrm{cm}^{-1}$ \\
\hline Testemunha & 268 & 95 & 207 & 6,7 & 0,13 & 0,44 & 0,31 & 579 & 1.449 \\
\hline Calcário & 267 & 98 & 235 & 6,98 & 0,14 & 0,42 & 0,31 & 606 & 1.473 \\
\hline Silicato & 264 & 95 & 232 & 6,99 & 0,13 & 0,42 & 0,3 & 603 & 1.463 \\
\hline Fcalc. & $0,05^{\text {ns }}$ & $0,49^{\text {ns }}$ & $1,24^{\mathrm{ns}}$ & $1,6^{\mathrm{ns}}$ & $0,51^{\mathrm{ns}}$ & $0,35^{\mathrm{ns}}$ & $0,28^{\text {ns }}$ & $1,28^{\text {ns }}$ & $1,71^{\mathrm{ns}}$ \\
\hline $\mathrm{CV}(\%)$ & 8,2 & 7,54 & 17,73 & 5,3 & 7,46 & 10,5 & 4,96 & 9,28 & 10 \\
\hline DMS & 23,45 & 7,82 & 45,99 & 0,39 & 0,02 & 0,05 & 0,02 & 60,99 & 30 \\
\hline
\end{tabular}

$* e^{\text {ns }}$, significativo a $1 \%, 5 \%$ e não significativo, respectivamente, pelo Teste F. Médias seguidas de letras distintas na coluna diferem estatisticamente pelo teste $\mathrm{t}(\mathrm{p}<0,05)$ 
Para as culturas do feijão (Tabela 7) e do guandu (Tabela 8), não foram detectadas diferenças significativas nos teores dos cátions solúveis, somatória de cátions e condutividade elétrica, da mesma forma que foi constatado por Silva e Lemos (2008) para as culturas do milheto, feijão e aveia preta. Com relação específica ao feijão submetido às doses de calcário, Soratto e Crusciol (2007) constataram ligeira alteração nos teores de $\mathrm{Ca}^{2+} \mathrm{e}$ $\mathrm{Mn}^{2+}$ solúveis, positiva e negativa respectivamente, porém tal variação não foi suficiente para promover alteração na condutividade elétrica dos extratos. Também trabalhando com doses de calcário em amendoim, Marques (2011) constatou diminuição nos teores de $\mathrm{Mn}^{2+}$ e $\mathrm{Fe}^{3+}$ solúveis nos extratos, sendo explicado pela elevação do $\mathrm{pH}$ do solo que provoca redução na disponibilidade desses cátions.

Pela análise conjunta dos dados, pode-se notar grande variação nos teores médios de cátions de cada cultura (Tabela 9). Observando-se estes valores, é possível inferir que as culturas gramíneas deste estudo apresentam comportamento diferente entre si, variando de espécie para espécie, evidenciando as constatações de Soratto e Crusciol (2007) e Meda et al. (2001), que não observaram semelhanças entre as gramíneas por eles estudadas.

Segundo Franchini et al. (2003), os resíduos vegetais que apresentam maior capacidade para mobilizar $\mathrm{Ca}^{2+}$ no perfil do solo são aqueles com alto teor de $\mathrm{K}^{+}$ solúvel em seus tecidos, em especial a aveia preta e o nabo forrageiro. Já resíduos com maiores teores de $\mathrm{Ca}^{2+}{\mathrm{e} \mathrm{Mg}^{2+}}^{2}$ solúveis, por sua vez, são mais eficientes em imobilizar o $\mathrm{Al}^{3+}$ da solução do solo, ocasionando uma maior neutralização desse elemento no perfil do solo. Desta forma, Moraes et al. (2007) constataram que $20 \mathrm{t} \mathrm{ha}^{-1} \mathrm{de}$ nabo forrageiro apresentaram influência relativamente pequena na mobilização de $\mathrm{Mg}$ para as camadas inferiores e na neutralização ou remoção do $\mathrm{Al}^{3+}$, sendo efetivo na mobilização de $\mathrm{K}^{+}$no perfil do solo.

Tabela 7 - Teores de cátions solúveis, somatória dos cátions ${ }^{(1)}$ e condutividade elétrica ${ }^{(2)}$ do extrato vegetal de feijão após a aplicação superficial de corretivos em Sistema de Semeadura Direta

\begin{tabular}{|c|c|c|c|c|c|c|c|c|c|}
\hline \multirow{3}{*}{ Tratamento } & \multicolumn{8}{|c|}{ Cátions solúveis no extrato vegetal de feijão } & \multirow{2}{*}{$\mathrm{CE}^{(2)}$} \\
\hline & $\mathrm{K}^{+}$ & $\mathrm{Ca}^{2+}$ & $\mathrm{Mg}^{2+}$ & $\mathrm{Mn}^{2+}$ & $\mathrm{Cu}^{2+}$ & $\mathrm{Fe}^{3+}$ & $\mathrm{Zn}^{2+}$ & $\Sigma^{(1)}$ & \\
\hline & \multicolumn{8}{|c|}{$\left(\mathrm{mmol}_{\mathrm{c}} \mathrm{kg}^{-1}\right)$} & $\mu \mathrm{S} \mathrm{cm}{ }^{-1}$ \\
\hline Testemunha & 261 & 303 & 199 & 3,98 & 0,23 & 0,40 & 0,38 & 770 & 1.270 \\
\hline Calcário & 266 & 307 & 203 & 3,99 & 0,25 & 0,40 & 0,36 & 782 & 1.266 \\
\hline Silicato & 266 & 300 & 201 & 3,83 & 0,25 & 0,38 & 0,36 & 772 & 1.262 \\
\hline $\mathrm{F}_{\text {calc. }}$ & $0,34^{\mathrm{ns}}$ & $0,91^{\mathrm{ns}}$ & $0,04^{\mathrm{ns}}$ & $0,30^{\mathrm{ns}}$ & $0,47^{\mathrm{ns}}$ & $0,93^{\mathrm{ns}}$ & $0,41^{\mathrm{ns}}$ & $0,10^{\mathrm{ns}}$ & $0,90^{\mathrm{ns}}$ \\
\hline $\mathrm{CV}(\%)$ & 4,81 & 10,5 & 11,82 & 11,28 & 14,95 & 9,88 & 13,11 & 6,98 & 13,25 \\
\hline DMS & 13,65 & 34,2 & 25,48 & 0,48 & 0,04 & 0,04 & 0,05 & 58,01 & 44,07 \\
\hline
\end{tabular}

$* \mathrm{e}^{\mathrm{ns}}$, significativo a $1 \%, 5 \%$ e não significativo, respectivamente, pelo Teste F. Médias seguidas de letras distintas na coluna diferem estatisticamente pelo teste $\mathrm{t}(\mathrm{p}<0,05)$

Tabela 8 - Teores de cátions solúveis, somatória dos cátions ${ }^{(1)}$ e condutividade elétrica ${ }^{(2)}$ do extrato vegetal de guandu após a aplicação superficial de corretivos em Sistema de Semeadura Direta

\begin{tabular}{|c|c|c|c|c|c|c|c|c|c|}
\hline \multirow{3}{*}{ Tratamento } & \multicolumn{8}{|c|}{ Cátions solúveis no extrato vegetal de guandu } & \multirow{2}{*}{$\mathrm{CE}^{(2)}$} \\
\hline & $\mathrm{K}^{+}$ & $\mathrm{Ca}^{2+}$ & $\mathrm{Mg}^{2+}$ & $\mathrm{Mn}^{2+}$ & $\mathrm{Cu}^{2+}$ & $\mathrm{Fe}^{3+}$ & $\mathrm{Zn}^{2+}$ & $\Sigma^{(1)}$ & \\
\hline & \multicolumn{8}{|c|}{$\left(\mathrm{mmol}_{\mathrm{c}} \mathrm{kg}^{-1}\right)$} & $\mu \mathrm{S} \mathrm{cm}^{-}$ \\
\hline Testemunha & 314 & 107 & 170 & 1,36 & 0,17 & 0,54 & 0,25 & 593 & 752 \\
\hline Calcário & 313 & 107 & 169 & 1,37 & 0,16 & 0,53 & 0,26 & 592 & 757 \\
\hline Silicato & 317 & 106 & 171 & 1,37 & 0,17 & 0,55 & 0,27 & 596 & 759 \\
\hline $\mathrm{F}_{\text {calc. }}$ & $0,09^{\mathrm{ns}}$ & $0,10^{\text {ns }}$ & $0,04^{\mathrm{ns}}$ & $0,24^{\mathrm{ns}}$ & $0,41^{\mathrm{ns}}$ & $0,16^{\mathrm{ns}}$ & $1,43^{\text {ns }}$ & $0,06^{\mathrm{ns}}$ & $0,45^{\mathrm{n}}$ \\
\hline $\mathrm{CV}(\%)$ & 5,43 & 10,1 & 6,21 & 19,74 & 11,6 & 16,3 & 10,2 & 5,94 & 11,6 \\
\hline DMS & 18,3 & 11,6 & 11,3 & 0,29 & 0,02 & 0,09 & 0,03 & 25,1 & 13,6 \\
\hline
\end{tabular}

$* \mathrm{e}^{\mathrm{ns}}$, significativo a $1 \%, 5 \%$ e não significativo, respectivamente, pelo Teste F. Médias seguidas de letras distintas na coluna diferem estatisticamente pelo teste $\mathrm{t}(\mathrm{p}<0,05)$ 
Tabela 9 - Teores de cátions solúveis, somatória dos cátions ${ }^{(1)}$ e condutividade elétrica ${ }^{(2)}$ do extrato vegetal das culturas de soja, braquiária, aveia branca, milheto, milho, feijão e guandu

\begin{tabular}{|c|c|c|c|c|c|c|c|c|c|}
\hline \multirow{3}{*}{ Cultura $^{(3)}$} & \multicolumn{8}{|c|}{ Cátions Solúveis } & \multirow{2}{*}{$\mathrm{CE}^{(2)}$} \\
\hline & $\mathrm{K}^{+}$ & $\mathrm{Ca}^{2+}$ & $\mathrm{Mg}^{2+}$ & $\mathrm{Mn}^{2+}$ & $\mathrm{Cu}^{2+}$ & $\mathrm{Fe}^{3+}$ & $\mathrm{Zn}^{2+}$ & $\Sigma^{(1)}$ & \\
\hline & \multicolumn{8}{|c|}{$\left(\mathrm{mmol}_{\mathrm{c}} \mathrm{kg}^{-1}\right)$} & $\mu \mathrm{S} \mathrm{cm}^{-1}$ \\
\hline Soja & $67,3 \mathrm{e}$ & $168 b$ & $256 a$ & $2,60 \mathrm{~d}$ & $0,69 \mathrm{a}$ & $0,98 \mathrm{a}$ & $1,12 b$ & $498 \mathrm{c}$ & $1.715 \mathrm{~d}$ \\
\hline Braquiária $^{(4)}$ & $275 b$ & $33,8 \mathrm{e}$ & $30,5 \mathrm{e}$ & $12,9 \mathrm{a}$ & $0,53 b$ & $0,99 \mathrm{a}$ & $0,94 \mathrm{c}$ & $354 d$ & $2.289 \mathrm{a}$ \\
\hline Av. branca & $200 \mathrm{c}$ & $88,2 d$ & $23,3 \mathrm{e}$ & $11,5 b$ & $0,31 \mathrm{~d}$ & $0,66 \mathrm{~b}$ & $0,15 f$ & $325 \mathrm{~d}$ & $1.746 \mathrm{c}$ \\
\hline Milheto & $153 \mathrm{~d}$ & $16,3 \mathrm{f}$ & $77,7 \mathrm{~d}$ & $12,5 \mathrm{ab}$ & $0,48 \mathrm{c}$ & $0,28 \mathrm{e}$ & $1,38 \mathrm{a}$ & $262 \mathrm{e}$ & $1.945 \mathrm{~b}$ \\
\hline Milho & $161 d$ & $45,6 \mathrm{e}$ & $18,7 \mathrm{e}$ & $8,00 \mathrm{c}$ & $0,32 d$ & $0,61 b c$ & $0,38 \mathrm{~d}$ & $235 f$ & $1.353 \mathrm{f}$ \\
\hline Braquiária( $^{(5)}$ & $263 b$ & $96,0 \mathrm{~cd}$ & $225 a$ & $6,89 \mathrm{c}$ & $0,13 f$ & $0,43 d$ & $0,31 \mathrm{de}$ & $596 \mathrm{~b}$ & $1.462 \mathrm{e}$ \\
\hline Feijão & $264 b$ & $303 a$ & $201 b$ & $3,90 \mathrm{~d}$ & $0,24 \mathrm{e}$ & $0,39 \mathrm{de}$ & $0,37 \mathrm{~d}$ & $773 a$ & $1.264 \mathrm{f}$ \\
\hline Guandu & $314 a$ & $107 \mathrm{c}$ & $170 \mathrm{c}$ & $1,30 \mathrm{e}$ & $0,17 \mathrm{f}$ & $0,54 \mathrm{c}$ & $0,26 \mathrm{e}$ & $594 b$ & $756 \mathrm{~g}$ \\
\hline $\mathrm{F}_{\text {calc. }}$ & $129 * *$ & $155^{* *}$ & $257 * *$ & $98,9 * *$ & $154 * *$ & $49,8^{* *}$ & $311^{* *}$ & $231^{* *}$ & $85,4^{* *}$ \\
\hline $\mathrm{CV}(\%)$ & 11,1 & 15,7 & 17,4 & 21,1 & 14,4 & 21,1 & 14,4 & 9,53 & 11,3 \\
\hline DMS & 19,6 & 13,9 & 18,5 & 1,27 & 0,04 & 0,10 & 0,07 & 36,00 & 144 \\
\hline
\end{tabular}

${ }^{(3)}$ valores médios da cultura, independentemente do tratamento; ${ }^{(4)} \mathrm{e}^{(5)}$ primeiro e segundo ano agrícola, respectivamente; $* *$, significativo a $1 \%$ pelo Teste F. Médias seguidas de letras distintas na coluna diferem estatisticamente pelo teste $\mathrm{t}(\mathrm{p}<0,05)$

Assim, as culturas com maior potencial de mobilização de $\mathrm{Ca}^{2+}$, segundo os dados obtidos no presente estudo, foram as leguminosas, feijão e guandu, e as gramíneas, braquiária e aveia branca. Quanto à neutralização de $\mathrm{Al}^{3+}$ a soja e o feijão foram as que apresentaram maior potencial.

A condutividade elétrica dos extratos vegetais determina a concentração dos íons dissolvidos na solução, onde os valores podem variar de acordo com a determinação da soma de cátions (MIYAZAWA, PAVAN; FRANCHINI, 2000). Para os valores referentes à condutividade dos extratos vegetais, não houve diferença significativa em todas as culturas avaliadas, em função da aplicação dos corretivos.

Comparando-se os extratos vegetais, nota-se que não existe uma correlação direta entre o somatório de cátions e a condutividade elétrica dos extratos vegetais. Tal correlação seria interessante, pois a determinação de condutividade elétrica é um método mais rápido e barato, que simplificaria a estimativa da quantidade de $\mathrm{H}^{+}$e $\mathrm{Al}^{3+}$ que pode ser neutralizada pelo material vegetal. Torna-se então necessária a quantificação dos cátions hidrossolúveis para expressar o potencial de mobilização de cátions e a neutralização de $\mathrm{Al}^{3+}$.

\section{CONCLUSÕES}

1. A concentração de cátions hidrossolúveis na parte aérea de culturas anuais foi igualmente influenciada pela aplicação de calcário e o silicato;
2. Culturas leguminosas possuem maior somatória de cátions quando comparadas às gramíneas;

3. A condutividade elétrica dos extratos vegetais não detecta variações nos teores e na somatória de cátions hidrossolúveis na parte aérea das culturas;

4. Os resíduos de feijão, guandu, braquiária e aveia branca são mais predispostos à lixiviar cátion no perfil do solo, já os de soja e feijão apresentam maior potencial de neutralizar o alumínio tóxico.

\section{AGRADECIMENTOS}

À FAPESP, pelo financiamento do projeto e pela concessão de bolsa de mestrado ao primeiro autor, e ao $\mathrm{CNPq}$, pela concessão de bolsa de produtividade em pesquisa ao segundo, e iniciação científica ao terceiro.

\section{REFERÊNCIAS}

BANZATTO, D. A.; KRONKA, S. N. Experimentação Agrícola. 3. ed. Jaboticabal: FUNEP, 1995. 247 p.

CAIRES, E. F.; BLUM, J.; BARTH, G. Alterações químicas do solo e resposta da soja ao calcário e gesso aplicados na implantação do sistema plantio direto. Revista Brasileira de Ciência do Solo, v. 23, p. 275-286, 2003. 
CASSIOLATO, M. E. et al. Evaluation of oat extracts on the efficiency of lime in soil. Brazilian Archives of Biology and Technology, v. 43, n. 05, p. 533-536, 2000.

DIEHL, R. C.; MIYAZAWA, M.; TAKAHASHI, H. W. Compostos orgânicos hidrossolúveis de resíduos vegetais e seus efeitos nos atributos químicos do solo. Revista Brasileira de Ciência do Solo, v. 32, p. 2653-2659, 2008. Número Especial.

EMPRESA BRASILEIRA DE PESQUISA AGROPECUÁRIA. Centro Nacional de Pesquisa de Solos. Sistema Brasileiro de Classificação de Solos. 2. ed. Rio de Janeiro, 2006. 306 p.

FRANCHINI, J. C. et al. Organic composition of green manures during growth and its effect on cation mobilization in an acid Oxisol. Communication in Soil Science and Plant Analysis, v. 34, n. 13, p. 2045-2058, 2003.

FRANCHINI, J. C. et al. Alterações químicas em solos ácidos após a aplicação de resíduos vegetais. Revista Brasileira de Ciência do Solo, v. 23, p. 533-542, 1999.

HARMSEN, K.; VLEK, P.L.G. The chemistry of micronutrients in soil. Fertility Research, v. 07, n. 01/03, p. 1-42, 1985.

KORNDÖRFER, G. H.; PEREIRA, H. S.; CAMARGO, M. S. Silicatos de cálcio e magnésio na agricultura. Uberlândia: GPSi - ICIAG - UFU, 2002. 23 p. (Boletim Técnico).

MA, J. F.; YAMAJI, N. Silicon uptake and accumulation in higher plants. Trends in Plant Science, v. 11, n. 08, p. 392-397, 2006.

MALAVOLTA, E. Avaliação do estado nutricional das plantas: princípios e aplicações, 2. ed. Piracicaba: POTAFOS, 1997. 319 p.

MARQUES, R. R. et al. Water-soluble nutrients in aerial plant parts of peanut and white oat as affected by lime and gypsum application. Revista Brasileira de Ciência do Solo, v. 35, n. 02, p. 513-12 522, 2011.
MEDA, A. R. et al. Alleviating soil acidity through plant organic compounds. Brazilian Archives of Biology and Technology, v. 44, n. 02, p. 185-189, 2001.

MIYAZAWA, M.; PAVAN, M. A.; FRANCHINI, J. C. Neutralização da acidez do perfil do solo por resíduos vegetais. Informações Agronômicas, n. 92, p. 01-08, 2000.

MORAES, M. F. et al. Mobilidade de íons em solo ácido com aplicação de calcário, ácido orgânico e material vegetal em superfície. Revista Brasileira de Ciência do Solo, v. 31, n. 04, p. 673-684, 2007.

PIERRE, W. H.; BANWART, W. L. Excess-base and excessbase/nitrogen ration of various crop species and parts of plant. Agronomy Journal, v. 65, n. 01, p. 91-96, 1973.

RAIJ, B. VAN et al. Análise química para avaliação da fertilidade de solos tropicais. Campinas: IAC, 2001. 284 p.

RAIJ, B. VAN et al. Recomendações de adubação e calagem para o Estado de São Paulo. 2. ed. Campinas: IAC, 1997. 285 p. (Boletim Técnico, 100).

ROSOLEM, C. A. et al. Potássio lixiviado da palha de aveia-preta e milheto após a dessecação química. Pesquisa Agropecuária Brasileira, v. 42, n. 08, p. 1169-1175, 2007.

SILVA, T. R. B.; LEMOS, L. B. Efeito da calagem superficial em plantio direto na concentração de cátions hidrossolúveis na parte aérea de culturas anuais. Revista Brasileira de Ciência do Solo, v. 32, n. 03, p. 1199-1207, 2008.

SORATTO, R. P.; CRUSCIOL, C. A. C. Cátions hidrossolúveis na parte aérea de culturas anuais mediante aplicação de calcário e gesso em superfície. Revista Brasileira de Ciência do Solo, v. 31, n. 01, p. 81-90, 2007. 